\title{
Study on Seepage Simulation of High Pressure Grouting in Microfractured Rock Mass
}

\author{
Kai Wang $(\mathbb{D}$, Lianguo Wang $(\mathbb{D}$, Bo Ren $(\mathbb{D}$, and Hao Fan \\ State Key Laboratory for Geomechanics and Deep Underground Engineering, China University of Mining and Technology, \\ Xuzhou 221116, China \\ Correspondence should be addressed to Lianguo Wang; cumt_lgwang@163.com
}

Received 11 November 2020; Revised 22 December 2020; Accepted 9 January 2021; Published 3 February 2021

Academic Editor: Jia Liu

Copyright (C) 2021 Kai Wang et al. This is an open access article distributed under the Creative Commons Attribution License, which permits unrestricted use, distribution, and reproduction in any medium, provided the original work is properly cited.

\begin{abstract}
In coal mines, under high in situ stress and strong mining activity, roadway surrounding rock commonly contains large amounts of larger fractures and microfractures. Along with the large deformation and continuous rheology of the soft rock roadway, the fractures in the surrounding rock are likely to be compressed and closed, forming undeveloped microfractures, which hinder conventional grouting support methods. Based on the fluid-solid coupling between slurry seepage and microfracture deformation, a theoretical model of microfracture grouting seepage is established. A program for the analysis and calculation of microfracture grouting is developed to quantitatively describe the variation in slurry seepage distance and fracture opening. Numerical experiments are carried out to study the grouting seepage of microfractures under different grouting pressures and fracture opening conditions, and the variation rules for the spatial distribution of fracture opening and slurry seepage distance during grouting pressure are obtained. Fluid-solid coupling has a significant influence on grout seepage characteristics. The grouting pressure and the fracture opening changes are nonlinearly attenuated along the grout seepage direction.
\end{abstract}

\section{Introduction}

With continuously decreasing shallow coal resources, deep well coal mining is the future of coal mine development [1, 2]. Different from shallow coal mines, deep coal mines exist in high in situ stress environments with strong mining action, and deep coal mine roadways are particularly difficult [3-5]. As a common engineering support technology, grouting support can significantly reinforcement and prevent seepage in the surrounding rock [6-10]. Slurry is injected into the fractures in the surrounding rock by grouting pressure, filling the fractures, and cementing the rock mass together to improve rock mass bearing capacity. Grouting support plays a vital role in the surrounding rock reinforcement [11].

Under high in situ stress and strong mining stress, surrounding rock masses commonly contain large amounts of fractures, including large- and medium-sized fractures as well as microfractures (fracture opening $d \leq 0.1 \mathrm{~mm}$ ) [1214]. With large deformation and continuous rheology of the surrounding rock, fractures in the rock mass are prone to squeezing and closing. A large number of underdeveloped and closed low-permeability microfractures exist in the surrounding rock [15-17]. Owing to the small fracture opening, cement particles cannot enter the microfractures, resulting in poor grouting and support effects as well as failure to achieve the expected reinforcement [18]. Subsequently, the roadway surrounding rock mass is seriously weakened, greatly reducing the overall stability of the surrounding rock [19-21].

Conventional grouting support is primarily carried out via lower grouting pressure. Based on infiltration theory, the grout spreads in the fractures or pores without destroying the structure of the rock mass [22]. However, due to the low permeability of microfractured rock masses, the injectability is poor. By increasing the grouting pressure, high pressure grouting technology can artificially reopen the originally closed fractures, improving the low-permeability of microfractured rock masses and achieving the desired support.

The grouting process is a process in which grout seepage and rock deformation are coupled together. Especially when the fracture opening is small, the fluid-solid coupling within the grouting process will be more significant $[23,24]$. The 


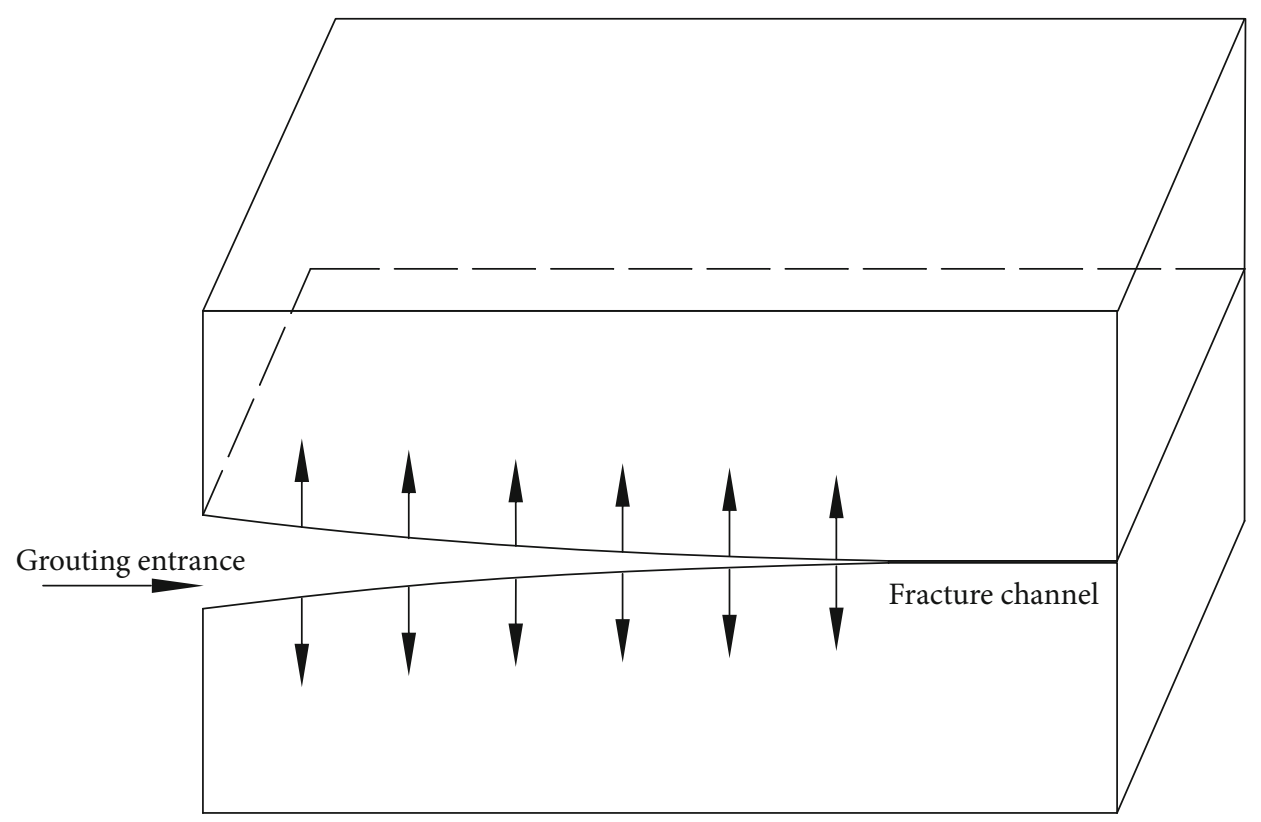

FiguRE 1: Schematic diagram of the slurry seepage process through a microfracture.

cement slurry enters the fracture due to grouting pressure, and the grouting pressure causes fracture to deform, changing the fracture opening and leading to variations in seepage characteristics $[25,26]$. Most of the existing grouting seepage simulations are aimed at the characteristics of the law of the slurry seepage movement and do not take into account the combined effect of the slurry seepage and rock mass deformation during the slurry seepage process [27]. Especially under high pressure grouting conditions, microfractures will deform under the action of grouting pressure, which will cause changes in the seepage characteristics of the slurry [28-31]. Existing grouting seepage simulations lack descriptions of fracture deformation and slurry seepage characteristics under high pressure grouting conditions and are not suitable for the simulation of microfractured high pressure grouting slurry seepage characteristics [32-34]. Therefore, studying the seepage characteristics of high pressure grouting on microfractures considering fluid-solid coupling is of great significance to the study of grouting in microfractured rock masses [35].

In order to study the seepage characteristics of high pressure grouting on microfractures, a theoretical high pressure grouting model is established. In addition, a quantitative description of slurry seepage and fracture deformation during high pressure grouting for microfractures under the action of fluid-solid coupling is realized by employing the step-wise algorithm.

\section{Methods}

2.1. Mathematical Model Establishment. During grouting, the slurry and fractures are coupled, and slurry seepage and fracture deformation affect each other. The amount of grouting pressure determines the change in the fracture opening, and the change in fracture opening also determines the resistance of the slurry seepage [36-39]. During slurry seepage, the grouting pressure and fracture opening at each position are attenuated to varying degrees, which affect the slurry seepage process [40].

The seepage process in microfractures under high pressure grouting is as follows: the cement slurry enters the microfracture under the action of grouting pressure, and the grout flows into the fracture and exerts force on the fracture surfaces on both sides [14, 41]. Microfractures are opened due to the grouting pressure, allowing more cement slurry to enter the fracture channels. Assuming that there is a critical pressure, when the force overcomes the critical pressure for fracture deformation, the fracture opens and deforms perpendicular to the fracture surface, and the opening amount of the fracture is positively related to grouting pressure. During cement slurry flow, the slurry is subject to its own viscosity and resistance caused by the fracture surface, such that the grouting pressure and the amount of fracture opening will be attenuated along the seepage direction during slurry seepage. The schematic diagram of the seepage process of slurry flow through a microfracture is shown in Figure 1.

2.2. Basic Assumptions. In this contribution, we make the following assumptions:

(i) The fractures are flat, the fracture openings are uniformly distributed, and gravity does not affect grouting seepage

(ii) The rock mass on both sides of the fracture is isotropic and homogeneous, the upper and lower surfaces of the fracture meet the nonslip boundary condition, and the slurry flow velocity on the surface of the fracture is zero

(iii) The influence of the flow of cement slurry in the direction perpendicular to the fracture surface on 
the spatial distribution of grouting pressure in the slurry seepage direction is ignored

(iv) Only elastic deformation occurs in the rock mass on both sides of the fracture

(v) Cement slurry seepage only occurs within the fracture, and the reduction of the slurry caused by the rock mass penetrating both sides of the fracture is ignored

2.3. Slurry Seepage Control Equation. The constitutive model for a Bingham fluid is shown in formula (1):

$$
\tau=\tau_{0}+\mu \frac{d v}{d r}
$$

In the formula, $\tau$ is the shear stress, $\mathrm{Pa} \cdot \mathrm{s}, \tau_{0}$ is the initial yield stress, $\mathrm{Pa} \cdot \mathrm{s}, \mu$ is the plastic viscosity $\mathrm{Pa} \cdot \mathrm{s}, v$ is the flow velocity, $\mathrm{m} / \mathrm{s}$, and $r$ is the microbody half height, $\mathrm{m}$.

We establish a rectangular coordinate system, in which the $x$ direction is the direction of the fracture centerline, and the $y$ direction is perpendicular to the fracture direction. The seepage model is shown in Figure 2. According to the force analysis of the microelement body, the shear stress distribution along the $x$ direction can be obtained as

$$
\tau=-r \frac{d p}{d x}
$$

The nucleus area of a Bingham fluid in the fracture centerline is

$$
r_{0}=-\tau_{0}\left(\frac{d x}{d p}\right)
$$

The range of the nuclear-retaining area needs to satisfy $r 0 \leq b / 2$. Substituting it into formula (3), the starting pressure gradient of the slurry movement can be obtained:

$$
\frac{d p}{d x}=\frac{2 \tau_{0}}{b}
$$

Combining equations (1) and (2) gives the differential equation for the slurry velocity in the $y$ direction:

$$
\frac{d v}{d r}=\frac{r}{\mu} \frac{d p}{d x}+\frac{\tau_{0}}{\mu} .
$$

When substituting the boundary condition $r= \pm b, v=0$, considering $|r| \leq r 0, v=v\left(r=r_{0}\right)$, the velocity of the slurry distribution along the fracture width is obtained:

$$
v=\left\{\begin{array}{cc}
-\frac{\mathrm{b}^{2}-4 \mathrm{r}^{2}}{8 \mu} \frac{\mathrm{dp}}{\mathrm{dx}}-\frac{\tau_{0}}{\mu}\left(\frac{\mathrm{b}}{2}-|\mathrm{r}|\right) & \left(r_{0} \leq|r| \leq \frac{\mathrm{b}}{2}\right) \\
-\frac{\mathrm{b}^{2}-4 \mathrm{r}^{2}}{8 \mu} \frac{\mathrm{dp}}{\mathrm{dx}}-\frac{\tau_{0}}{\mu}\left(\frac{\mathrm{b}}{2}-\mathrm{r}_{0}\right) & |\mathrm{r}| \leq r_{0}
\end{array} .\right.
$$

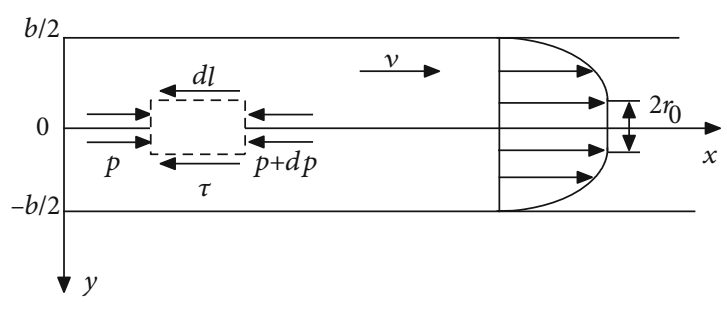

FIgURE 2: Bingham fluid seepage model.

Integrating the slurry flow velocity in the $y$ direction and taking the average slurry velocity gives

$$
\begin{aligned}
\bar{v} & =\frac{b^{2}}{12 \mu}\left[-\frac{d p}{d x}-3 \frac{\tau_{0}}{b}+\frac{4 \tau_{0}^{3}}{b^{3}(d p / d x)^{2}}\right] \\
& =\frac{-b^{2}}{12 \mu} \frac{d p}{d x}\left(1+3 \frac{\tau_{0}}{b} \frac{d x}{d p}-\frac{4 \tau_{0}^{3}}{b^{3}(d p / d x)^{3}}\right) .
\end{aligned}
$$

Substituting into equation (3) and ignoring the influence of higher order terms on the slurry, the average slurry flow velocity is

$$
\bar{v}=\frac{-b^{2}}{12 \mu} \frac{d p}{d x}\left(1+3 \frac{r_{0}}{b}-\frac{4 \tau_{0}^{3}}{b^{3}}\right) .
$$

In formula (8), we make

$$
A=1+3 \frac{r_{0}}{b}-\frac{4 \tau_{0}^{3}}{b^{3}} .
$$

Then, obtain the slurry flow control equation:

$$
\frac{d p}{d x}=\frac{-12 \mu \bar{v}}{A b^{2}} .
$$

2.4. Fracture Deformation Control Equation. For microfractured rock masses, fracture surfaces are held in contact due to the in situ stress, which causes the force between the fracture surfaces to affect the fracture deformation [21]. During grouting, the cement slurry flows in the fractures and produces stress opposite to the in situ stress on the fracture surfaces. Assuming that there is a critical grouting pressure, when the grouting pressure is less than the critical pressure, the fracture opening does not change. When the grouting pressure is greater than the critical pressure, the grouting pressure causes the fracture to open, and the fracture opening degree increases with increasing grouting pressure. In this contribution, a constant pressure grouting method is adopted, meaning that the grouting pressure at the grouting port remains constant. During slurry seepage, the grouting pressure gradually decreases with increasing seepage distance. When the grouting pressure is less than the critical pressure, the fracture opening remains unchanged. When the grouting pressure is greater than the critical pressure, the fracture opening near the grouting port changes. As the seepage distance of the slurry increases, grouting pressure decreases. When grouting pressure decreases to the critical 


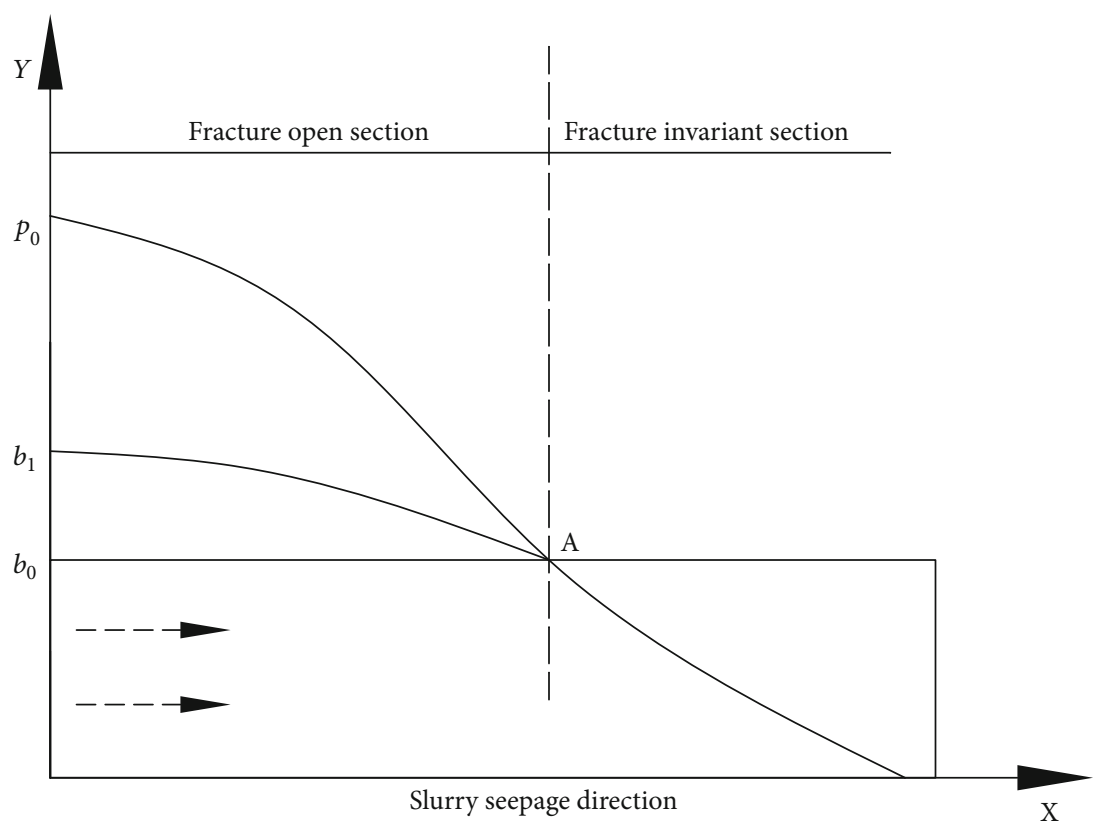

FiguRE 3: Curve of fracture opening and grouting pressure.

pressure, the fracture stops opening and stays the same. The curve of the fracture opening degree and grouting pressure is shown in Figure 3.

The governing equation of fracture opening during grouting can be obtained as [21]

$$
b=\left\{\begin{array}{ll}
b_{0} & \left(p<p_{1}\right) \\
b_{0}+k_{n}\left(p-p_{1}\right) & \left(p>p_{1}\right)
\end{array} .\right.
$$

In the formula, $b$ is the fracture opening, $\mathrm{m}, b_{0}$ is the initial fracture opening, $\mathrm{m}, p$ is the grouting pressure, $\mathrm{MPa}, p_{1}$ is the critical grouting pressure, $\mathrm{MPa}, k_{n}$ is the normal elastic coefficient, $k_{n}=D / E, D$ is the grouting influence range, $\mathrm{m}$, and $E$ is the rock mass elastic modulus, $\mathrm{Pa}$.

\subsection{Step-Wise Algorithm for Microfracture High Pressure} Grouting Seepage Process. Based on the step-wise algorithm, a microfracture high pressure grouting process analysis and calculation program is developed using the MATLAB software platform. The slurry seepage area is discrete using the same time interval $\Delta t$, and the slurry seepage area is divided into $n$ finite elements. Combined with the fracture opening control equation, the recursive method is used to determine the time-step iterative solution according to the law of conservation of energy, which describes the grout seepage distance and fracture opening changes throughout the grouting process. The schematic diagram of the step-wise algorithm is shown in Figure 4.

The iterative calculation process for grout seepage and fracture deformation is as follows: for $m$ iterations, the fracture opening $b_{i}^{m}$ of each element node and the slurry seepage distance $L_{i}^{m}$ of each element are obtained, and the grouting pressure $p_{j}^{m}$ at each element node is determined using the recursion method. The obtained grouting pressure $p_{j}^{m}$ is then used to recalculate the new fracture opening $b_{i}^{m+1}$ and slurry seepage distance $L_{i}^{m+1}$, as well as judge whether the slurry seepage distance $L_{i}^{m+1}$ at this time meets the convergence condition. If the convergence requirement is met, the current time step ends, and the next time step is calculated. If the convergence requirement is not met, the iteration continues until the convergence requirement is met.

The relative error between any two iteration results is

$$
\varepsilon=\left|\frac{\sum_{i=1}^{n} L_{i}^{m}-\sum_{i=1}^{n} L_{i}^{m-1}}{\sum_{i=1}^{n} L_{i}^{m}}\right| .
$$

$\sum_{i=1}^{n} L_{i}^{m}$ is the slurry seepage distance calculated after the nth iteration. When the error is less than $0.1 \%$, the convergence condition is satisfied. When the convergence conditions are met, the seepage distance of each unit, the grouting pressure of each unit node, and the fracture opening are output.

The step-wise algorithm calculation flow chart written by MATLAB is shown in Figure 5.

\section{Results and Discussion}

3.1. Seepage Characteristic Analysis. The grouting cement is composed of a 1000 mesh ultrafine cement slurry, the water-cement ratio is 1.2 , and the slurry flow pattern is that of a Bingham fluid, the measured slurry viscosity $\mu=0.02$ Pa.s, the slurry yield stress $\tau_{0}=3.3 \mathrm{~Pa}$, and the original fracture opening $b=100 \mu \mathrm{m}$. When the grouting pressure is $3 \mathrm{MPa}$, grouting time is $100 \mathrm{~s}$, and the fracture opening is $100 \mu \mathrm{m}$ (Figures 6 and 7). The spatial distribution curves of the grouting pressure and the fracture opening are obtained, respectively, with or without considering fluid-solid coupling. 


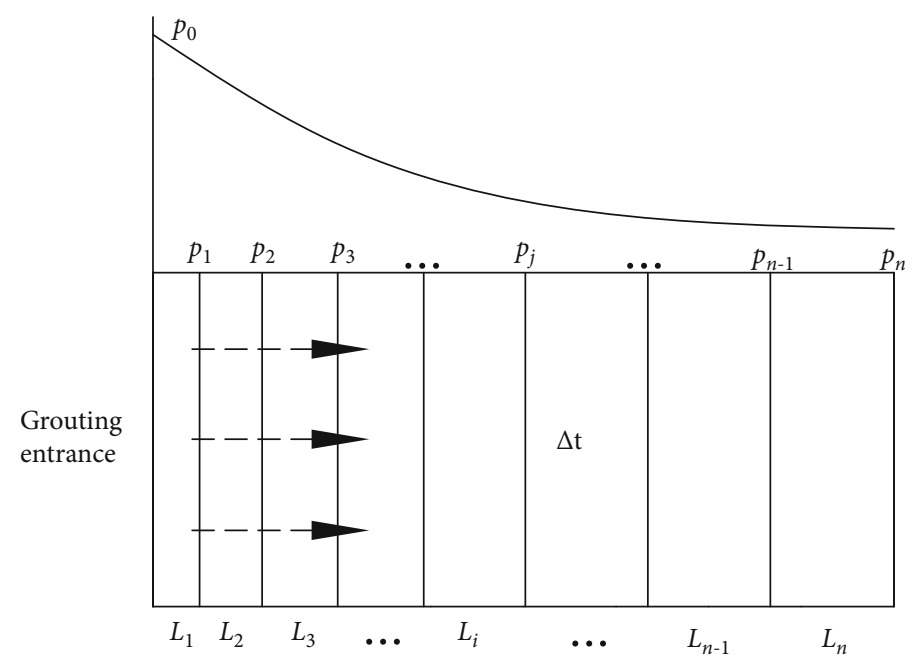

FIGURE 4: Schematic diagram of the step-wise algorithm. $L_{i}$ represents the grout seepage distance of each grouting time unit $(i=1 \sim n)$, and $p_{j}$ represents the grouting pressure of the node after each grouting time unit $(j=1 \sim n)$.

When fluid-solid coupling is not considered, the grouting pressure decays linearly from the entrance along the slurry seepage direction, the fracture opening remains unchanged at $100 \mu \mathrm{m}$, and the slurry seepage distance is $5 \mathrm{~m}$. When fluid-solid coupling is considered, the grouting pressure and fracture opening both decrease nonlinearly from the entrance in the slurry seepage direction. The maximum fracture opening at the grouting entrance is $180 \mu \mathrm{m}, 1.8$ times the original fracture opening, and the slurry seepage distance is $6.4 \mathrm{~m} .4 .78 \mathrm{~m}$ away from the grouting entrance, the grouting pressure decays to the critical pressure. At this time, the fracture opening is reduced to the original fracture opening of $100 \mu \mathrm{m}$, and the fracture opening remains unchanged with increasing distance from the entrance. When grouting pressure is reduced to the critical grouting pressure, the grouting pressure changes from the original nonlinear decrease to a linear decrease. After grouting pressure is reduced to the extent that the fracture opening cannot be changed, the fracture opening remains the original value. When fluid-solid coupling is considered under the same grouting conditions, the grout seepage distance is larger than that without considering the fluid-solid coupling..

In order to examine the variation in fracture opening with grouting time at different positions $(1 \mathrm{~m}, 2 \mathrm{~m}, 3 \mathrm{~m}$, $4 \mathrm{~m}$, and $5 \mathrm{~m}$ ) from the grouting entrance, the variation curve of fracture opening vs. grouting time was obtained. The slurry pressure change curves are shown in Figures 8 and 9, respectively.

When the grouting time is $10 \mathrm{~s}$, the fracture opening at $1 \mathrm{~m}$ away from the grouting inlet increases to $130 \mu \mathrm{m}$, while the fracture opening at $2 \mathrm{~m}, 3 \mathrm{~m}, 4 \mathrm{~m}$, and $5 \mathrm{~m}$ away from the grouting entrance remained at $100 \mu \mathrm{m}$, without any change in fracture opening (Figure 8). When the grouting time is $20 \mathrm{~s}$, the fracture opening at $1 \mathrm{~m}$ and $2 \mathrm{~m}$ away from the grouting entrance increases to $150 \mu \mathrm{m}$ and $108 \mu \mathrm{m} \mathrm{mm}$, respectively. The fracture opening at $3 \mathrm{~m}, 4 \mathrm{~m}$, and $5 \mathrm{~m}$ away from the grouting entrance remained at $100 \mu \mathrm{m}$ without any change in fracture opening. With increasing grouting time, the fracture opening at $1 \mathrm{~m}$ away from the grouting entrance increases from $130 \mu \mathrm{m}$ at $10 \mathrm{~s}$ to $150 \mu \mathrm{m}$, an increase of $20 \mu \mathrm{m}$. When the grouting time is $40 \mathrm{~s}$, the fracture openings at $1 \mathrm{~m}, 2 \mathrm{~m}$, and $3 \mathrm{~m}$ away from the grouting entrance increases to $160 \mu \mathrm{m}, 134 \mu \mathrm{m}$, and $101 \mu \mathrm{m}$, respectively. The fracture opening at $4 \mathrm{~m}$ and $5 \mathrm{~m}$ away from the grouting entrance remained at $100 \mu \mathrm{m}$, without any change in fracture opening. When the grouting time is $80 \mathrm{~s}$, the fracture openings at $1 \mathrm{~m}, 2 \mathrm{~m}, 3 \mathrm{~m}$, and $4 \mathrm{~m}$ away from the grouting entrance increases to $167 \mu \mathrm{m}, 150 \mu \mathrm{m}, 131 \mu \mathrm{m}$, and $108 \mu \mathrm{m}$, respectively. The fracture opening at $5 \mathrm{~m}$ away from the grouting entrance remained at $100 \mu \mathrm{m}$ without any change in fracture opening. When the grouting time is $120 \mathrm{~s}$, the fracture openings at $1 \mathrm{~m}, 2 \mathrm{~m}, 3 \mathrm{~m}, 4 \mathrm{~m}$, and $5 \mathrm{~m}$ away from the grouting entrance increases to $170 \mu \mathrm{m}, 157 \mu \mathrm{m}, 142 \mu \mathrm{m}$, $125 \mu \mathrm{m}$, and $106 \mu \mathrm{m}$, respectively. The fracture opening at different positions gradually increases with increasing grouting time. The farther from the grouting entrance is, the later the change in fracture opening is, and the smaller the change in the fracture opening is. With continuously increasing grouting time, the coupling effect between fracture opening and slurry pressure continues, and the fracture opening continues to change; however, the influence degree gradually decreases.

When the grouting time is $10 \mathrm{~s}$, the grouting pressure at $1 \mathrm{~m}$ and $2 \mathrm{~m}$ away from the grouting entrance is $1.84 \mathrm{MPa}$ and $0.04 \mathrm{MPa}$, respectively (Figure 9). When the grouting time increases to $40 \mathrm{~s}$, the grouting pressure at $1 \mathrm{~m}, 2 \mathrm{~m}$, $3 \mathrm{~m}$, and $4 \mathrm{~m}$ away from the grouting entrance is $2.47 \mathrm{MPa}$, $1.84 \mathrm{MPa}, 1.02 \mathrm{MPa}$, and $0.04 \mathrm{MPa}$, respectively. When the grouting time increases to $80 \mathrm{~s}$, the grouting pressure at $1 \mathrm{~m}, 2 \mathrm{~m}, 3 \mathrm{~m}, 4 \mathrm{~m}$, and $5 \mathrm{~m}$ away from the grouting inlet is $2.64 \mathrm{MPa}, 2.22 \mathrm{MPa}, 1.75 \mathrm{MPa}, 1.19 \mathrm{MPa}$, and $0.49 \mathrm{MPa}$, respectively. With continuously increasing grouting time, the grouting pressure gradually decreases compared to the initial grouting stage, and with increasing grouting time, the scope of influence will increase, and the degree of influence will relatively decrease. 


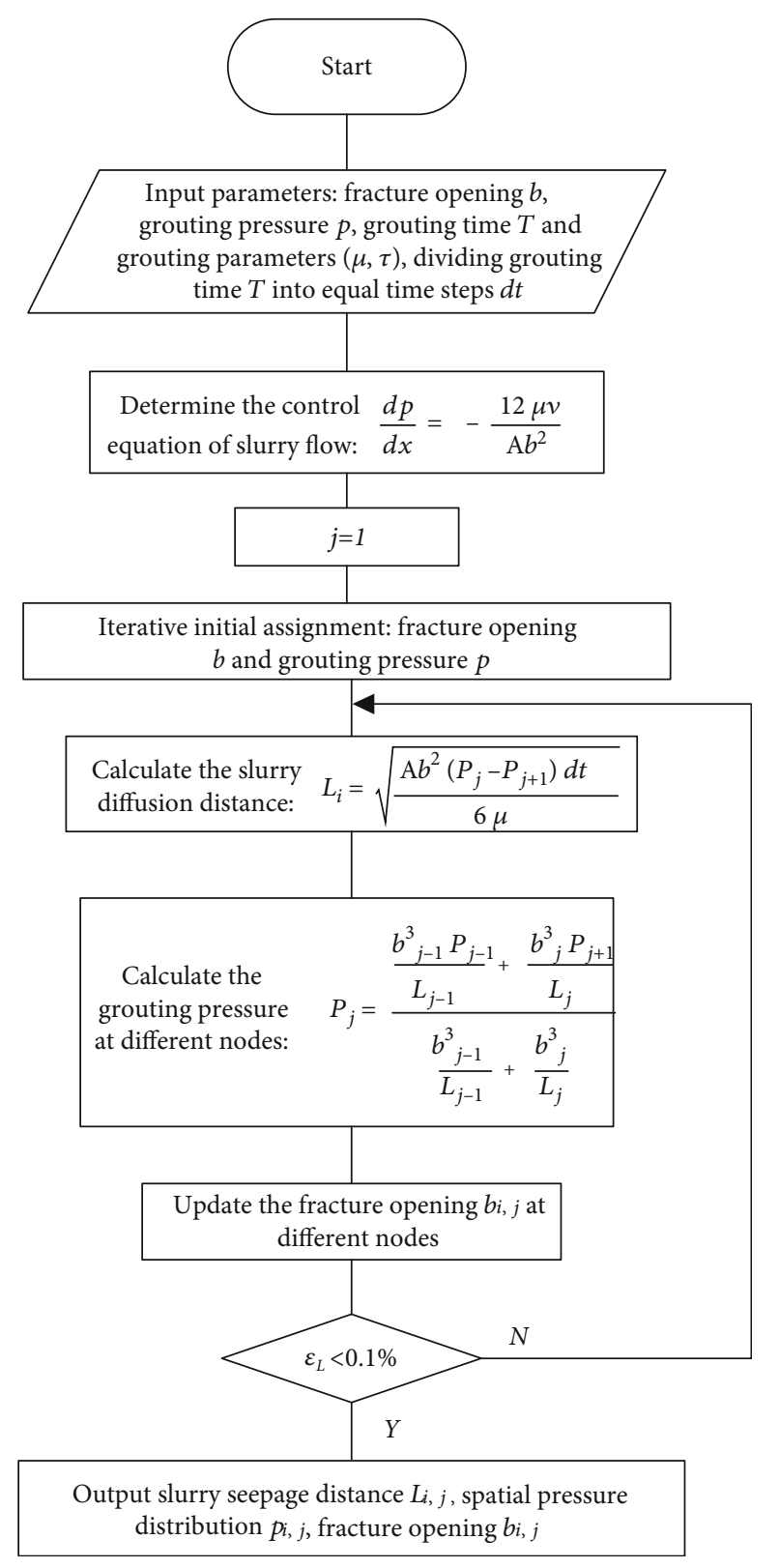

FIgURE 5: Flow chart of the step-wise algorithm.

3.2. Influence of Fracture Opening. When the grouting pressure is $3 \mathrm{MPa}$, and grouting time is $100 \mathrm{~s}$, the relationship between slurry seepage distance and grouting time under varying fracture opening conditions $(20 \mu \mathrm{m}, 50 \mu \mathrm{m}, 100 \mu \mathrm{m}$, $200 \mu \mathrm{m}$, and $300 \mu \mathrm{m}$ ) was calculated, and the influence of fracture opening on slurry seepage characteristics was analyzed (Figures 10 and 11).

Without considering fluid-solid coupling, when the fracture opening is $20 \mu \mathrm{m}$, the slurry seepage distance increases from $0.31 \mathrm{~m}$ at a grouting time of $10 \mathrm{~s}$ to $0.89 \mathrm{~m}$ at a grouting time of $80 \mathrm{~s}$, an increase of $0.58 \mathrm{~m}$ (Figures 10 and 11). When the fracture opening is $100 \mu \mathrm{m}$, the slurry seepage distance increases from $1.58 \mathrm{~m}$ at a grouting time of $10 \mathrm{~s}$ to $4.47 \mathrm{~m}$ at a grouting time of $80 \mathrm{~s}$. When the fracture opening is $300 \mu \mathrm{m}$, the slurry seepage distance increases from $4.74 \mathrm{~m}$ at $10 \mathrm{~s}$ to $13.41 \mathrm{~m}$ at $80 \mathrm{~s}$. Considering the effect of fluidsolid coupling, when the fracture opening is $20 \mu \mathrm{m}$, the slurry seepage distance increases from $0.78 \mathrm{~m}$ at $10 \mathrm{~s}$ to $2.2 \mathrm{~m}$ at $80 \mathrm{~s}$. When the fracture opening is $100 \mu \mathrm{m}$, the slurry seepage distance increases from $2.02 \mathrm{~m}$ at $10 \mathrm{~s}$ to $5.72 \mathrm{~m}$ at $80 \mathrm{~s}$. When the fracture opening is $300 \mu \mathrm{m}$, the slurry seepage distance increases from $5.17 \mathrm{~m}$ at $10 \mathrm{~s}$ to $14.62 \mathrm{~m}$ at $80 \mathrm{~s}$. Fracture opening has a significant influence on the slurry seepage distance. With increasing grouting time, the slurry seepage distance also increases. With increasing fracture opening at the same grouting time, the slurry seepage distance also increases. In the early stage of grouting seepage, the slurry seepage rate is relatively fast. As grouting continues, the slurry seepage rate gradually decreases. The larger the fracture opening is, the larger the grouting seepage rate will be. As fracture opening gradually decreases, the seepage rate of the grout will decrease accordingly.

In order to examine the influence of fracture opening on the spatial distribution characteristics of grouting pressure for a grouting pressure of $3 \mathrm{MPa}$ and grouting time of $100 \mathrm{~s}$, the conditions of different fracture openings $(20 \mu \mathrm{m}, 50 \mu \mathrm{m}$, $100 \mu \mathrm{m}, 200 \mu \mathrm{m}$, and $300 \mu \mathrm{m}$ ) in the grouting simulation are analyzed. The spatial distribution curve of grouting pressure is shown in Figure 12.

For a fracture opening of $20 \mu \mathrm{m}$, the grouting pressure decays rapidly in the slurry seepage direction and decreases to 0 at $2.64 \mathrm{~m}$ from the grouting entrance (Figure 12). When the fracture opening is small, the slurry seepage resistance is very large, which rapidly reduces the grouting pressure inside the fracture and affects the slurry seepage. When the fracture opening is $50 \mu \mathrm{m}$, the grouting pressure decreases rapidly in the slurry seepage direction and decreases to 0 at $3.92 \mathrm{~m}$ from the grouting entrance; however, the reduced rate is smaller than that when the fracture opening is $20 \mu \mathrm{m}$. With increasing fracture opening, when the fracture opening is $300 \mu \mathrm{m}$, the grouting pressure decreases to 0 at $16.4 \mathrm{~m}$ from the grouting entrance. Results show that the smaller the fracture opening, the greater the decay grouting pressure rate and the shorter the seepage distance. With increasing fracture opening, grouting pressure decay rate decreases, and the slurry seepage distance increases.

3.3. Influence of Grouting Pressure. In order to examine the influence of grouting pressure on the grout seepage distance, calculate whether the grout diffusion distance with fluid-solid coupling under different grouting pressures (1 $\mathrm{MPa}, 2 \mathrm{MPa}$, $3 \mathrm{MPa}, 5 \mathrm{MPa}$, and $8 \mathrm{MPa}$ ) and choose the fracture opening, the relationship between grouting pressure, and grout seepage distance of the grout when the grouting time is $100 \mu \mathrm{m}$ and grouting time of $100 \mathrm{~s}$ is analyzed. The simulation results are shown in Figure 13.

Under a grouting pressure of $1 \mathrm{MPa}$, the slurry seepage distance is $2.38 \mathrm{~m}$ when fluid-solid coupling is not considered, and the slurry seepage distance is $2.88 \mathrm{~m}$ when fluidsolid coupling is considered. When considering fluid-solid coupling, the slurry seepage distance is slightly larger than that without considering fluid-solid coupling; however, there is little difference between them. When grouting pressure increases to $3 \mathrm{MPa}$, the slurry seepage distance is $5 \mathrm{~m}$ without 


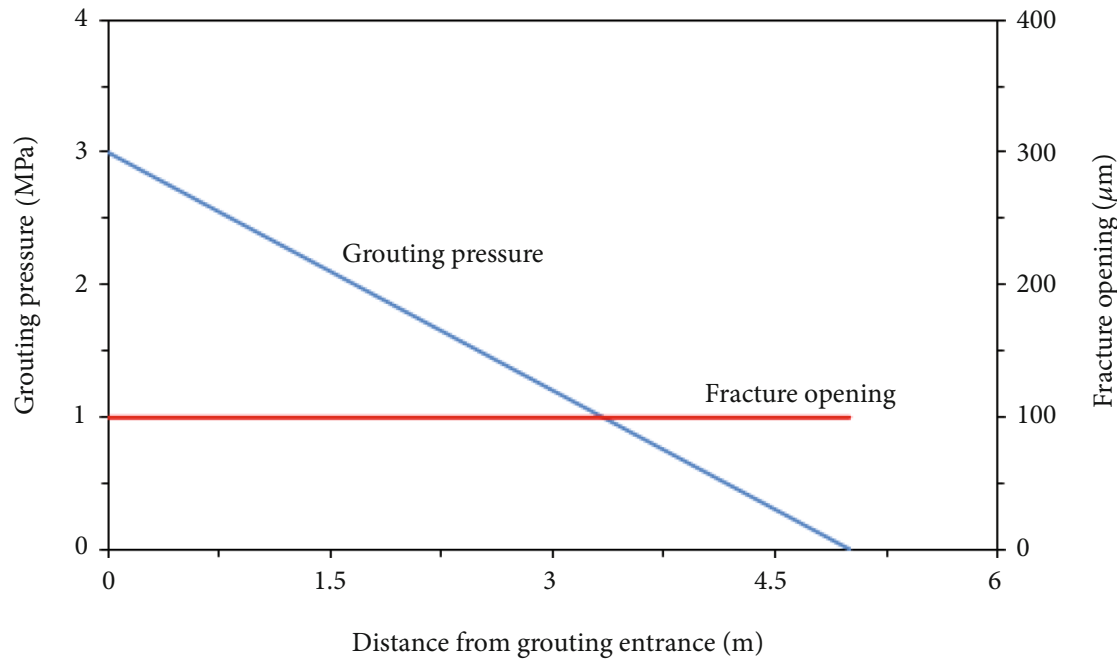

FIGURE 6: The curve of grouting pressure and fracture opening with no fluid-solid coupling.

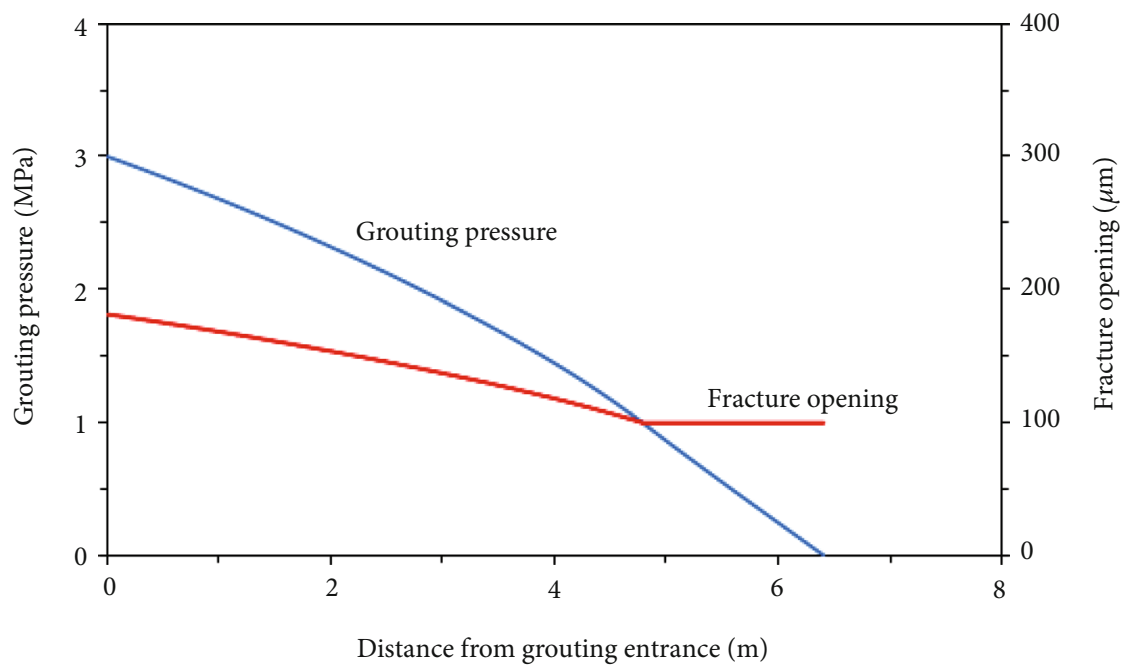

FIGURE 7: The curve of grouting pressure and fracture opening with fluid-solid coupling.

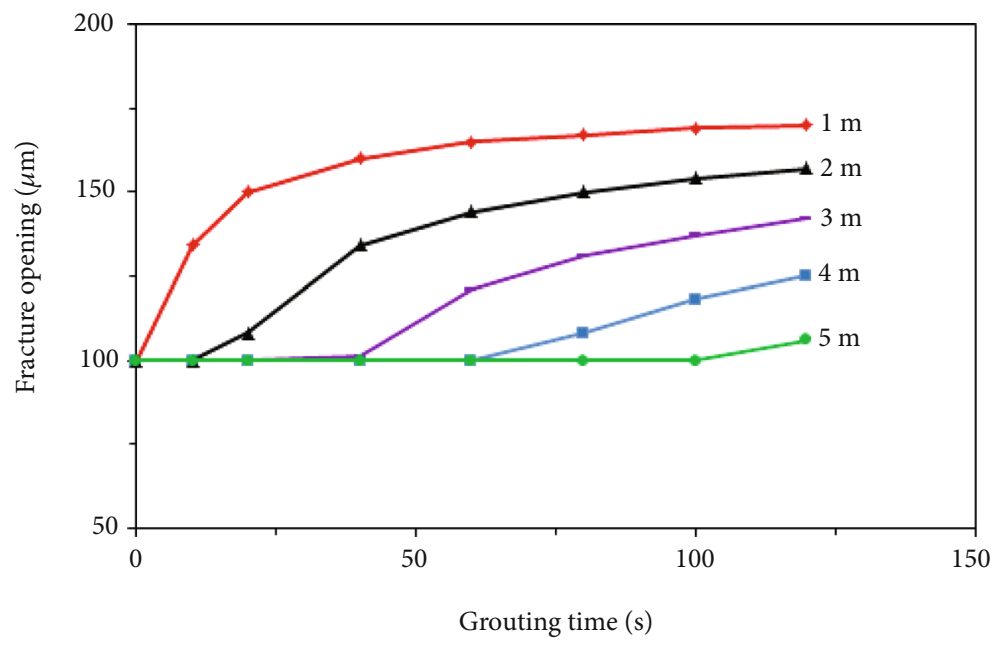

Figure 8: Curves of fracture opening vs. grouting time. 


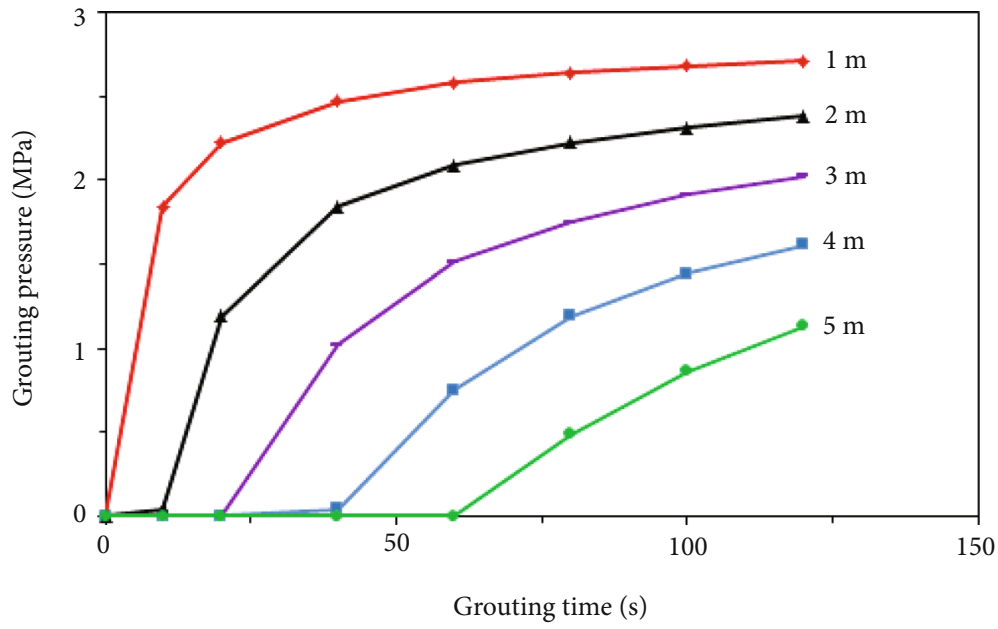

FIGURE 9: Curves of grouting pressure vs. grouting time.

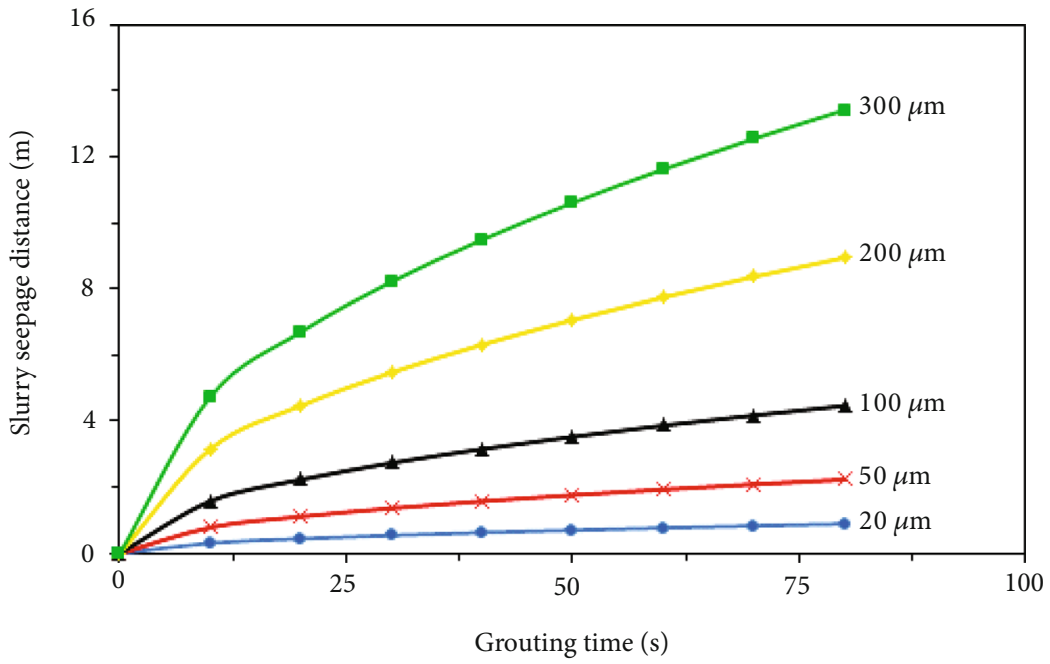

FIGURE 10: Slurry seepage distance for different fracture openings with no fluid-solid coupling.

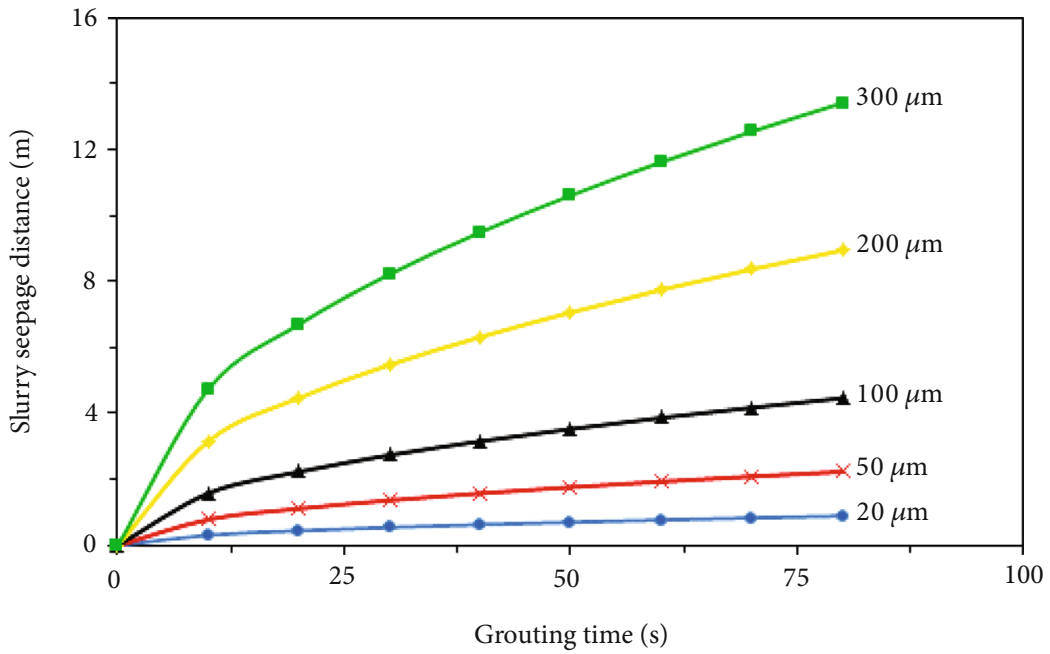

FIGURE 11: Slurry seepage distance for different fracture openings with fluid-solid coupling. 


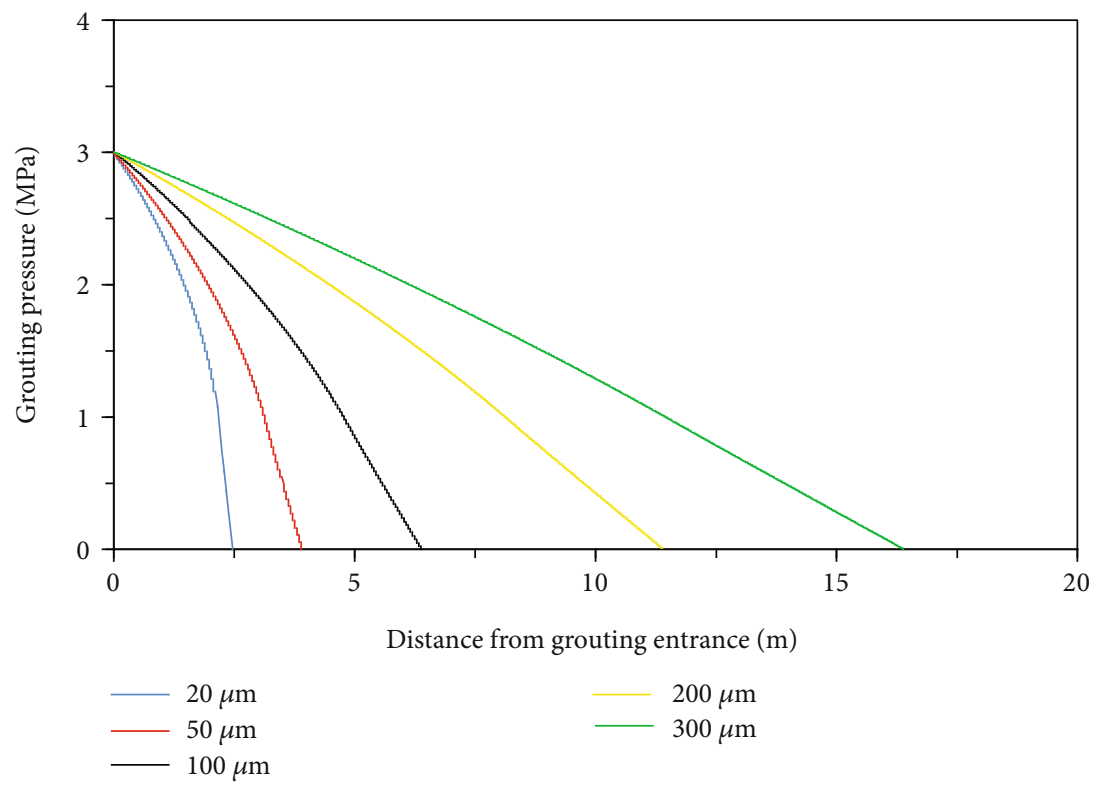

FIGURE 12: Curve of grouting pressure vs. distance for different fracture openings.

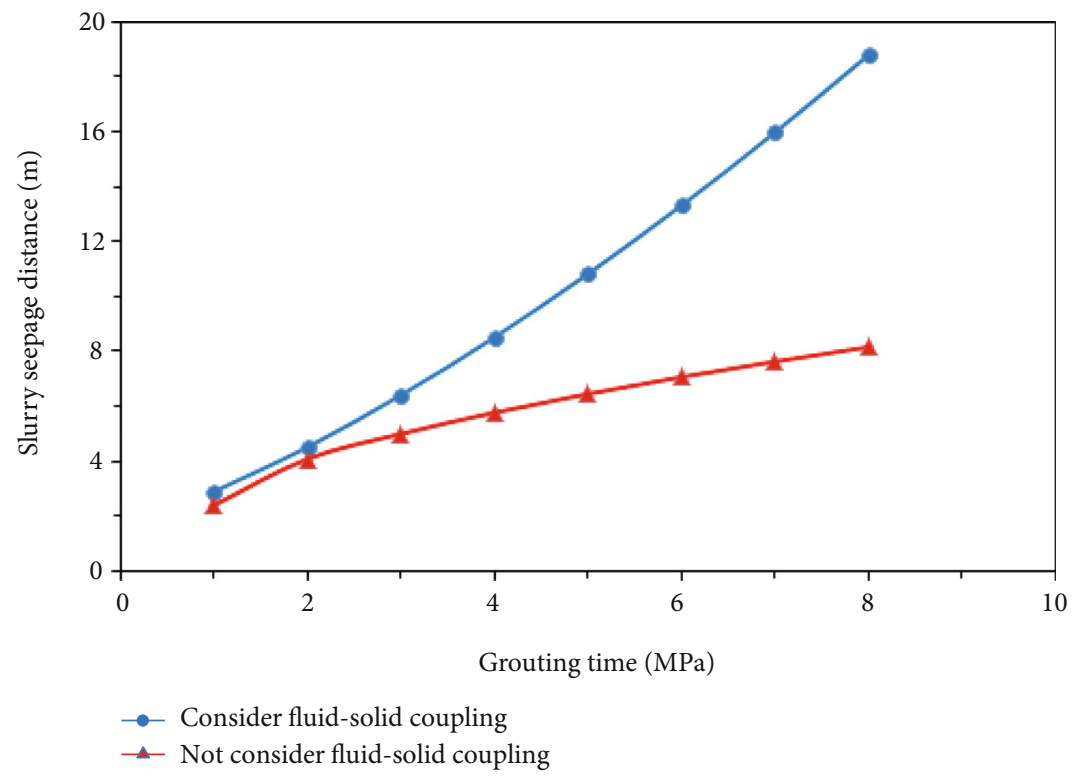

FIGURE 13: Slurry seepage distance under different grouting pressures.

considering fluid-solid coupling, and the slurry seepage distance increases by $2.62 \mathrm{~m}$. Considering fluid-solid coupling, the slurry seepage distance is $6.41 \mathrm{~m}$, and the slurry seepage distance increases by $3.53 \mathrm{~m}$. When grouting pressure increases to $8 \mathrm{MPa}$, the slurry seepage distance is $8.16 \mathrm{~m}$ without considering fluid-solid coupling and $18.81 \mathrm{~m}$ when considering fluid-solid coupling. With increasing grouting pressure, the slurry seepage distance only increases from $2.38 \mathrm{~m}$ to $8.16 \mathrm{~m}$ without considering fluid-solid coupling; while when considering fluid-solid coupling, the slurry seepage distance increases from $2.88 \mathrm{~m}$ at the beginning to $18.8 \mathrm{~m}$. When fluid-solid coupling is not considered, the resistance to slurry seepage is greater due to the constant fracture opening, and the slurry seepage distance is much smaller than that under fluid-solid coupling. When considering fluid-solid coupling, with increasing grouting pressure, the fracture opening also increases, the resistance of slurry seepage decreases, and the slurry seepage distance increases.

In order to study the influence of grouting pressure on fracture opening, the law between fracture opening change and grouting pressure under different grouting pressures (1 $\mathrm{MPa}, 2 \mathrm{MPa}, 3 \mathrm{MPa}, 5 \mathrm{MPa}$, and $8 \mathrm{MPa}$ ) was calculated, and various grouting pressures were obtained. The grouting pressure change curve and the fracture opening change curve 


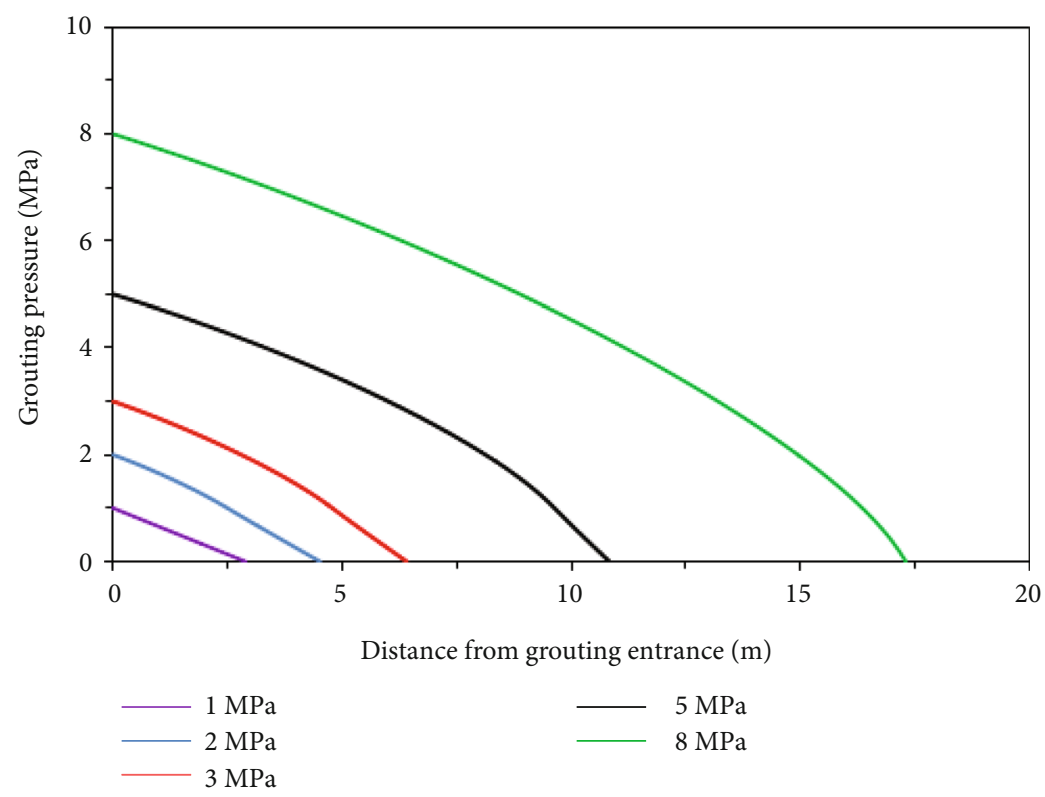

FigURE 14: Curve of grouting pressure vs. distance for different grouting pressures.

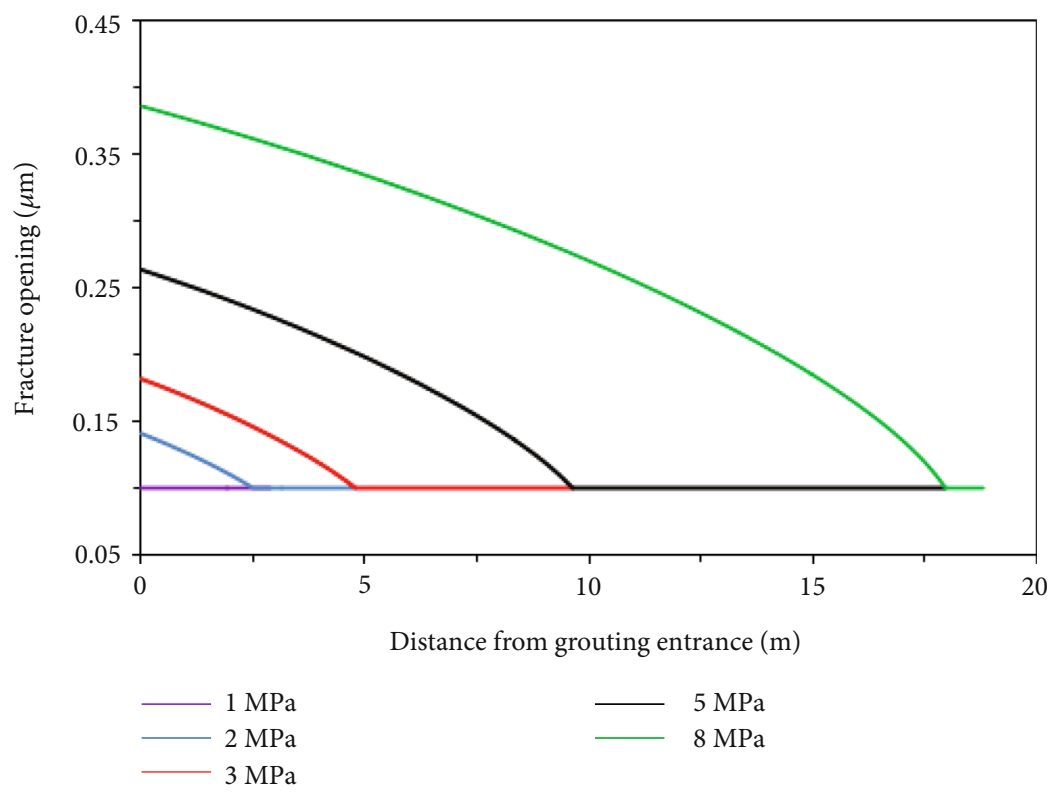

FIGURE 15: Curve of fracture opening vs. distance for different grouting pressures.

at different positions from the grouting inlet under pressure are shown in Figures 14 and 15, respectively.

As shown in Figures 14 and 15, when the grouting pressure is $1 \mathrm{MPa}$, grouting pressure decreases linearly along the slurry seepage direction and decreases to 0 at $2.86 \mathrm{~m}$ from the grouting entrance. The fracture opening remains unchanged at $100 \mu \mathrm{m}$. The grouting pressure is less than the critical pressure; therefore, the fracture opening does not change. When the grouting pressure increases to $2 \mathrm{MPa}$, the grouting pressure shows nonlinear attenuation along the slurry seepage direction, and when the grouting pressure is less than the critical pressure, the grouting pressure curve shows linear attenuation until it decreases to 0 at
$4.51 \mathrm{~m}$ from the grouting entrance. The fracture opening at the fracture entrance is the most affected. The original fracture opening increases from $100 \mu \mathrm{m}$ to $180 \mu \mathrm{m}$ and shows nonlinear attenuation along the slurry seepage direction. With decreasing grouting pressure to the critical pressure, the fracture opening remains unchanged. When grouting pressure increases to $5 \mathrm{MPa}$, the grouting pressure also shows nonlinear attenuation along the grouting seepage direction. When the grouting pressure in the fracture channel attenuates to less than the critical pressure, the grouting pressure curve shows linear attenuation, until it decreases to 0 at $18.8 \mathrm{~m}$ from the grouting entrance. The fracture opening value at the entrance of the grouting increases to $380 \mu \mathrm{m}$, 
and it also decays nonlinearly along the grout seepage direction until the fracture opening remains unchanged. At the same position from the grouting entrance, as grouting pressure increases, the increase in the fracture opening also increases. The increase in fracture opening at the entrance of grouting is the largest, and it gradually decreases along the slurry seepage direction.

Overall, the change in grouting pressure and fracture opening shows a nonlinear attenuation trend during fracture seepage. As grouting pressure decreases nonlinearly along the slurry seepage direction, the fracture opening also decreases nonlinearly. When grouting pressure decreases to the critical pressure, the fracture opening decreases to the original fracture opening and remains unchanged until the slurry stops flowing. With increasing grouting pressure, the increase in fracture opening also increases, from $80 \mu \mathrm{m}$ when the grouting pressure is $2 \mathrm{MPa}$ to $280 \mu \mathrm{m}$ when the grouting pressure is $8 \mathrm{MPa}$. Correspondingly, the affected fracture opening range also increases, from $2.5 \mathrm{~m}$ at $2 \mathrm{MPa}$ to $17.96 \mathrm{~m}$ at $8 \mathrm{MPa}$, which is significantly affected by the grouting pressure.

\section{Conclusions}

(i) A step-wise algorithm in MATLAB was used to conduct numerical experiment on grouting slurry seepage in microfractures. The slurry seepage area is divided into multiple finite elements at the same time interval. According to the law of conservation of energy and the recursion method, a time-step iterative solution is used to quantitatively describe the change in grout seepage distance and fracture opening during grouting

(ii) Fluid-solid coupling has a significant influence on slurry seepage characteristics. At the same grouting time, the slurry seepage distance increases with increasing fracture opening. In the early stage of grout seepage, the slurry seepage rate is faster. With increasing grouting time, the slurry seepage rate gradually decreases, and the greater the fracture opening, the greater the slurry seepage rate

(iii) The grouting pressure and fracture opening are largest at the grouting entrance. Along the slurry seepage direction, the change in grouting pressure and fracture opening shows nonlinear attenuation trend. When grouting pressure decreases to the critical pressure, the fracture opening is linearly attenuated, and the fracture opening remains unchanged until the slurry stops flowing

\section{Data Availability}

The data used to support the findings of this study are included within the article.

\section{Conflicts of Interest}

The authors declare that they have no conflicts of interest regarding the publication of this paper.

\section{Acknowledgments}

We thank all project partners for many fruitful discussions. This paper was funded by the National Key Research and Development Program of China (2017YFC0603004) and the China Postdoctoral Science Foundation Funded Project (2020M671649).

\section{References}

[1] X. Chen, L. Li, L. Wang, and L. Qi, "The current situation and prevention and control countermeasures for typical dynamic disasters in kilometer-deep mines in China," Safety Science, vol. 115, pp. 229-236, 2019.

[2] W. Qiao, W. Li, and X. Zhang, "Characteristic of water chemistry and hydrodynamics of deep karst and its influence on deep coal mining," Arabian Journal of Geosciences, vol. 7, no. 4, pp. 1261-1275, 2014.

[3] Y. Sun, G. Li, J. Zhang, and J. Xu, "Failure mechanisms of rheological coal roadway," Sustainability, vol. 12, no. 7, p. 2885 , 2020.

[4] Z. Xiao, J. Liu, S. Gu et al., "A control method of rock burst for dynamic roadway floor in deep mining mine," Shock and Vibration, vol. 2019, 16 pages, 2019.

[5] Y. Xue, Z. Cao, F. Du, and L. Zhu, "The influence of the backfilling roadway driving sequence on the rockburst risk of a coal pillar based on an energy density criterion," Sustainability, vol. 10, no. 8, p. 2609, 2018.

[6] M. Heidari and F. Tonon, "Ground reaction curve for tunnels with jet grouting umbrellas considering jet grouting hardening," International Journal of Rock Mechanics and Mining Sciences, vol. 76, pp. 200-208, 2015.

[7] R. Pan, Q. Wang, B. Jiang et al., "Failure of bolt support and experimental study on the parameters of bolt- grouting for supporting the roadways in deep coal seam," Engineering Failure Analysis, vol. 80, pp. 218-233, 2017.

[8] X. Sun, L. Wang, Y. Lu, B. Jiang, Z. Li, and J. Zhang, "A yielding bolt-grouting support design for a soft-rock roadway under high stress: a case study of the Yuandian No. 2 coal mine in China," Journal of the Southern African Institute of Mining and Metallurgy, vol. 118, no. 1, pp. 71-82, 2018.

[9] K. Wang, L. Wang, B. Ren, and H. Fan, "Understanding the effect of cementitious grouting pressure on micro-fracture permeability for rock reinforcement underground: a lab study," Energies, vol. 13, no. 16, p. 4225, 2020.

[10] Q. Wang, Q. Qin, B. Jiang, H. C. Yu, R. Pan, and S. C. Li, "Study and engineering application on the bolt-grouting reinforcement effect in underground engineering with fractured surrounding rock," Tunnelling and Underground Space Technology, vol. 84, pp. 237-247, 2019.

[11] X. Ni, C. Xu, and W. Li, "Numerical simulation of grouting in micro-fractured rock mass of metro tunnel considering effect of fluid-solid coupling," Tunnel Construction, vol. 38, no. 10, p. 1667, 2018.

[12] F.-j. Dong, Y. Cao, D.-z. Ren, and W. Sun, "Micro-fracture development impact factors analysis and its effects on well production of Hua-qing area Ordos Basin in China," International Journal of Oil Gas and Coal Technology, vol. 21, no. 1, pp. 39-56, 2019.

[13] M. Ezati, M. Azizzadeh, M. A. Riahi, V. Fattahpour, and J. Honarmand, "Characterization of micro-fractures in 
carbonate Sarvak reservoir, using petrophysical and geological data, SW Iran," Journal of Petroleum Science and Engineering, vol. 170, pp. 675-695, 2018.

[14] H. Sun, L. Duan, L. Liu et al., "The influence of micro-fractures on the flow in tight oil reservoirs based on pore-network models," Energies, vol. 12, no. 21, p. 4104, 2019.

[15] P. Wang, Z. Wang, L. Shen, and L. Xin, "Lattice Boltzmann simulation of fluid flow characteristics in a rock microfracture based on the pseudo-potential model," Energies, vol. 11, no. 10, p. 2576, 2018.

[16] P. Zhu, C. Lin, H. Ren, Z. Zhao, and H. Zhang, "Micro-fracture characteristics of tight sandstone reservoirs and its evaluation by capillary pressure curves: a case study of Permian sandstones in Ordos Basin, China," Journal of Natural Gas Science and Engineering, vol. 27, pp. 90-97, 2015.

[17] Y. Xue, Y. Liu, F. Dang et al., "Assessment of the nonlinear flow characteristic of water inrush based on the Brinkman and Forchheimer seepage model," Water, vol. 11, no. 4, p. 855, 2019

[18] Y. Li, C. Wu, and B.-A. Jang, "Effect of bedding plane on the permeability evolution of typical sedimentary rocks under triaxial compression," Rock Mechanics and Rock Engineering, vol. 53, no. 11, pp. 5283-5291, 2020.

[19] L. Wang, M. Li, and X. Wang, "Study of mechanisms and technology for bolting and grouting in special soft rock roadways under high stress," Chinese Journal of Rock Mechanics and Engineering, vol. 24, no. 16, pp. 2889-2893, 2005.

[20] J. Yang, Y. Cheng, and W. Chen, "Experimental study on diffusion law of post-grouting slurry in sandy soil," Advances in Civil Engineering, vol. 2019, 11 pages, 2019.

[21] L. Zhang, Q. Zhang, R. Liu, and S. Li, "Grouting mechanism in fractured rock considering slurry-rock stress coupling effects," Chinese Journal of Geotechnical Engineering, vol. 40, no. 11, pp. 2003-2011, 2018.

[22] H. Jiang, R. Zhong, and Z. Peng, "Study on preparation of chemical grouting and its hydraulic properties and application for water seepage safety," Journal of Coastal Research, vol. 94, no. sp1, p. 291, 2019.

[23] P. Li, Q. Zhang, X. Zhang, S. Li, X. Li, and J. Zuo, "Grouting diffusion characteristics in faults considering the interaction of multiple grouting," International Journal of Geomechanics, vol. 17, no. 5, article 04016117, 2017.

[24] B. T. Sun, X. Z. Ling, C. Ling, and G. R. Zhu, "Numerical simulation for diffusion and pressure distribution of permeation grouting," Journal of Hydraulic Engineering, vol. 38, no. 11, pp. 1402-1407, 2007.

[25] X. X. Zhang, J. G. Wang, F. Gao, and X. L. Wang, "Numerical study of fracture network evolution during nitrogen fracturing processes in shale reservoirs," Energies, vol. 11, no. 10, 2018.

[26] X. Zhang, J. G. Wang, X. Wang, and F. Gao, "Numerical simulations on the front motion of water permeation into anisotropic porous media," Geofluids, vol. 2019, 13 pages, 2019.

[27] Y. Wang, B. Liu, and Y. Qi, "A risk evaluation method with an improved scale for tunnel engineering," Arabian Journal for Science and Engineering, vol. 43, no. 4, pp. 2053-2067, 2018.

[28] M. Axelsson and G. Gustafson, "The PenetraCone, a new robust field measurement device for determining the penetrability of cementitious grouts," Tunnelling and Underground Space Technology, vol. 25, no. 1, pp. 1-8, 2010.

[29] A. Draganović and H. Stille, "Filtration and penetrability of cement-based grout: study performed with a short slot,"
Tunnelling and Underground Space Technology, vol. 26, no. 4, pp. 548-559, 2011.

[30] S. Mohajerani, A. Baghbanan, G. Wang, and S. F. Forouhandeh, "An efficient algorithm for simulating grout propagation in 2D discrete fracture networks," International Journal of Rock Mechanics and Mining Sciences, vol. 98, pp. 67-77, 2017.

[31] Z. Saada, J. Canou, L. Dormieux, and J. C. Dupla, "Evaluation of elementary filtration properties of a cement grout injected in a sand," Canadian Geotechnical Journal, vol. 43, no. 12, pp. 1273-1289, 2006.

[32] X. Chen, L.-s. Xu, and M. Xu, “Adaptive control system for grouting pressure stability based on fuzzy algorithm," Journal of Intelligent \& Fuzzy Systems, vol. 31, no. 4, pp. 2231-2239, 2016.

[33] H. Stromsvik, J. C. Morud, and E. Grov, "Development of an algorithm to detect hydraulic jacking in high pressure rock mass grouting and introduction of the PF index," Tunnelling and Underground Space Technology, vol. 81, pp. 16-25, 2018.

[34] Y. Xue, T. Teng, F. Dang, Z. Ma, S. Wang, and H. Xue, "Productivity analysis of fractured wells in reservoir of hydrogen and carbon based on dual-porosity medium model," International Journal of Hydrogen Energy, vol. 45, no. 39, pp. 20240-20249, 2020.

[35] J. Liu, X. Liang, Y. Xue, K. Yao, and Y. Fu, "Numerical evaluation on multiphase flow and heat transfer during thermal stimulation enhanced shale gas recovery," Applied Thermal Engineering, vol. 178, p. 115554, 2020.

[36] G. Dai, Z. Zhang, G. Shi, S. Li, W. Shi, and X. Li, "Study on anti-seepage slurry of landfill site modified by sodium carboxymethyl cellulose," International Journal of Modern Physics B, vol. 33, no. 31, p. 1950377, 2019.

[37] G. Dai, J. Zhu, and G. Shi, "Analysis on the basic properties of PBFC anti-seepage slurry in landfill," Applied Ecology and Environmental Research, vol. 16, no. 6, pp. 7657-7667, 2018.

[38] W. Zhang, H. Zhou, and W. Guo, "Experimental study on seepage characteristics of fractured rock mass and its electrical response," Journal of Hydrologic Engineering, vol. 24, no. 7, article 04019017, 2019.

[39] S. Zhou, X. Zhang, D. Wu, and H. Di, "Mathematical modeling of slurry infiltration and particle dispersion in saturated sand," Transport in Porous Media, vol. 124, no. 1, pp. 91-116, 2018.

[40] J. Liu, K. Yao, Y. Xue, X. Zhang, Z. Chong, and X. Liang, "Study on fracture behavior of bedded shale in three-pointbending test based on hybrid phase-field modelling," Theoretical and Applied Fracture Mechanics, vol. 104, article 102382, 2019.

[41] H. Xie, Y. Ju, S. Ren, F. Gao, J. Liu, and Y. Zhu, "Theoretical and technological exploration of deep in situ fluidized coal mining," Frontiers in Energy, vol. 13, no. 4, pp. 603-611, 2019. 